\title{
Resveratrol potentiates rapamycin to prevent hyperinsulinemia and obesity in male mice on high fat diet
}

\author{
OV Leontieva ${ }^{1}$, G Paszkiewicz ${ }^{1}$ ZN Demidenko ${ }^{1}$ and MV Blagosklonny ${ }^{\star, 1}$
}

High doses of rapamycin, an antiaging agent, can prevent obesity in mice on high fat diet (HFD). Obesity is usually associated with hyperinsulinemia. Here, we showed that rapamycin given orally, at doses that did not affect weight gain in male mice on HFD, tended to decrease fasting insulin levels. Addition of resveratrol, which alone did not affect insulin levels, potentiated the effect of rapamycin, so that the combination decreased obesity and prevented hyperinsulinemia. Neither rapamycin nor resveratrol, and their combination affected fasting levels of glucose (despite lowering insulin levels), implying that the combination might prevent insulin resistance. We and others previously reported that resveratrol at high doses inhibited the mTOR (Target of Rapamycin) pathway in cell culture. Yet, as we confirmed here, this effect was observed only at superpharmacological concentrations. At pharmacological concentrations, resveratrol did not exert 'rapamycin-like effects' on cellular senescence and did not inhibit the mTOR pathway in vitro, indicating nonoverlapping therapeutic mechanisms of actions of rapamycin and resveratrol in vivo. Although, like rapamycin, resveratrol decreased insulin-induced HIF-1-dependent transcription in cell culture, resveratrol did not inhibit mTOR at the same concentrations. Given distinct mechanisms of action of rapamycin and resveratrol at clinically relevant doses, their combination warrants further investigation as a potential antiaging, antiobesity and antidiabetic modality.

Cell Death and Disease (2013) 4, e472; doi:10.1038/cddis.2012.202; published online 24 January 2013

Subject Category: Experimental Medicine

The mTOR (Target of Rapamycin) pathway is involved in cellular senescence, organismal aging and age-related diseases. ${ }^{1-8}$ Rapamycin prolongs life span in heterozygous, inbred and cancer-prone mice. ${ }^{9-16}$ It was shown that rapamycin prevents weight gain in mice on a high fat diet (HFD) ${ }^{17}$ However, in some (but not all) studies chronic administration of high-dose rapamycin led to glucose intolerance and insulin resistance. ${ }^{18-23}$ For example, Chang et al reported that everyday administration of rapamycin by interperitoneal injections caused insulin resistance. ${ }^{20}$ This insulin resistance, however, resembles starvation diabetes or condition associated with severe calorie restriction and may extend life span. ${ }^{24,25}$ In fact, all studies in mice showed that rapamycin extends life span rather than shortens it. Still observed insulin resistance caused by high-dose rapamycin in mice may complicate its introduction for prevention and treatment of age-related metabolic diseases in humans and may preclude its widespread use. Theoretical considerations suggest that intermittent administration of rapamycin orally might not have side effects of high chronic doses. Here, we attempt to prevent metabolic abnormalities of obesity by intermittent oral administration of rapamycin. Independently, resveratrol was intensively studied as antiaging agent to prevent age-related diseases. ${ }^{26-28}$ Resveratrol prevents insulin resistance in mice ${ }^{29,30}$ and even extends life span of mice on HFD. ${ }^{29}$ In obese mice, relatively low-dose of resveratrol lowered fasting blood glucose level and serum insulin, increased hepatic glycogen content and ameliorated fatty liver without change in body weight. ${ }^{31}$ Furthermore, resveratrol improves insulin sensitivity in type 2 diabetic patients. $^{32}$ Resveratrol has multiple targets, including sirtuins. ${ }^{30,33-36}$ It was also shown that resveratrol inhibits the mTOR/S6K pathway in cell culture. ${ }^{37-39}$ Yet, to inhibit mTOR, resveratrol was used at high near-toxic concentrations, which may exceed pharmacologically achievable concentrations in animals. ${ }^{40-43}$ Here, we investigated whether addition of resveratrol would potentiate effects of rapamycin in mice. Complementing in vivo research, we demonstrated in cell culture that, at pharmacological doses, resveratrol does not inhibit the mTOR pathway, suggesting that rapamycin and resveratrol act by different mechanisms.

\section{Results}

Low dose rapamycin does not prevent weight gain in male mice on HFD. Mice were fed either regular food or high fat (60\% fat) diet (Figure 1). On HFD mice progressively

\footnotetext{
${ }^{1}$ Department of Cell Stress Biology, Roswell Park Cancer Institute, BLSC, L3-312, Elm and Carlton Streets, Buffalo 14263, NY, USA

*Corresponding author: Professor MV Blagosklonny, Department of Cell Stress Biology, Roswell Park Cancer Institute, BLSC, L3-312, Elm and Carlton Streets, Buffalo 14263, USA. Tel: + 716845 3326; Fax: + 716845 3944; E-mail: blagosklonny @oncotarget.com

Keywords: MTOR; rapamycin; aging; diabetes; cancer; insulin; obesity

Abbreviations: CS, Chronological senescence; FBS, fetal bovine serum; HFD, high fat diet; HIF, Hypoxia inducible factor; HRE, HIF-responsive element; IGF-1, Insulin-like growth factor -1; IPTG, isopropyl-thio-galactosidase; MTOR, Mechanistic Target of Rapamycin; RD, regular diet; RPE, retinal pigment epithelial; TOR, Target of Rapamycin

Received 30.11.12; accepted 4.12.12; Edited by G Melino
} 


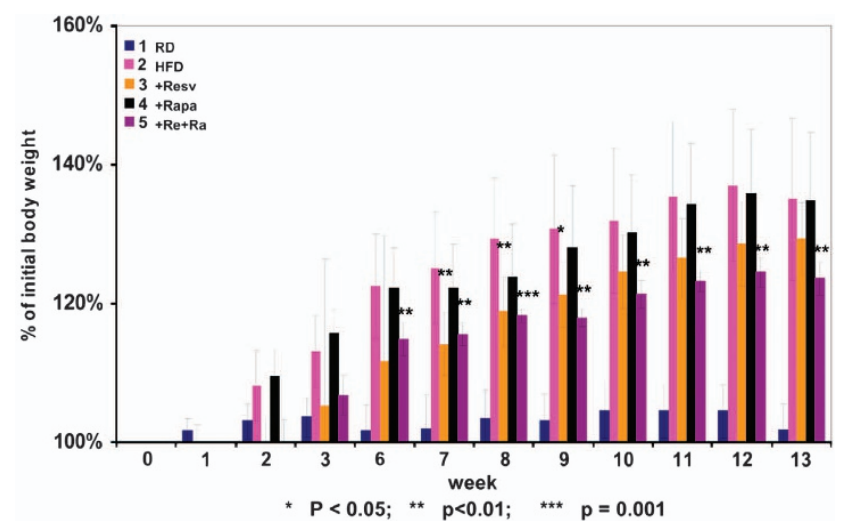

Figure 1 Body weight of mice on HFD with or without treatment. Initial body weight of each mouse is taken for 100 percent. Change of the weight was determined once a week. 1: RD; 2: HFD; 3: HFD + resv (resveratrol); 4: HFD + Rapa (rapamycin); $5:$ HFD + Re + Ra ( + resveratrol + rapamycin in combination). Data present mean \pm S.E.M. Statistically significant differences were assessed using Student's t-test

gained weight, reaching plateau after 12 weeks (group 2; $\mathrm{HF}$ ). Other mice on HFD were subdivided into 3 groups, which received treatment with resveratrol (group 3), rapamycin (group 4) and resveratrol + rapamycin (group 5). The dose of rapamycin was chosen, as such that it did not significantly prevent weight gain in male mice on HFD. Noteworthy, similar schedules of rapamycin administration significantly prevented weight gain in female mice on HFD (Figure 2). First, female mice were more sensitive to rapamycin compared with male mice. Second, female mice were more prone to weight gain than males (Figure 2), so that the effect of treatment with rapamycin was easier to detect in females than in males. Resveratrol only transiently (weeks $7-8$ ) decreased weight gain (Figure 1). In contrast, a combination of rapamycin and resveratrol prevented weight gain with high level of significance (Figure 1; $P<0.01$ starting from week 6 and $P<0.001$ at week 8 ).

Rapamycin and resveratrol prevent hyperinsulinemia in mice on HFD. After 13 weeks of treatment, blood was collected after overnight fasting in all mice. There was a three fold increase in fasting insulin levels in mice on HFD (Figure 3a). All the mice on HFD had higher levels of insulin than regular diet mice. Noteworthy, while 8 out of 10 mice on HFD had equal levels of insulin (which were higher than levels in any mouse on regular diet), two mice had exceptionally high levels of insulin. The uniform shift to higher levels of insulin in mice on HFD may represent 'normal elevation' of insulin associated with obesity and/or aging. Two exacerbated cases can be viewed as obesity-induced disease, because the levels of insulin in these two mice deviated from the 'normal' elevation of insulin, observed in mice on HFD. Thus, disease can be viewed as exacerbated 'normal' trend associated with HFD (or with aging in other cases). Administrated separately, both resveratrol and rapamycin decreased HFD-induced hyperinsulinemia albeit the effect was not statistically significant. A combination of resveratrol and rapamycin significantly prevented hyperinsulinemia $(P=0.0023)$. In resveratrol plus rapamycin-treated

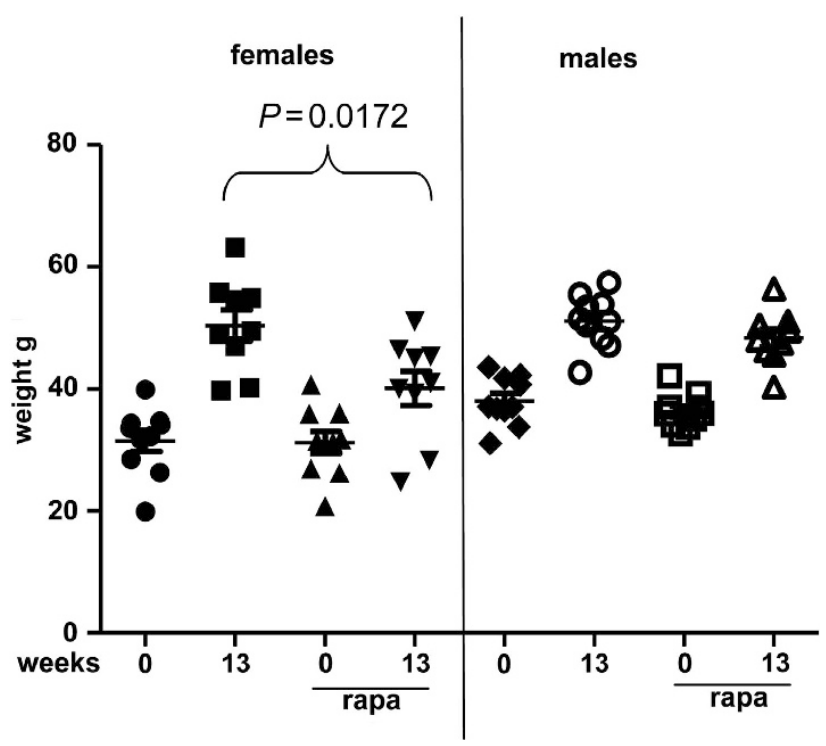

Figure 2 Effects of HFD and rapamycin on body weight: comparison of male and female mice. Body weight of each mouse was determined at the beginning of the experiment ( 0 weeks) and 13 weeks after the initiation of HFD, and treatment with rapamycin in females and males of similar age (42 and 38.3 weeks, respectively). Data present mean \pm S.E.M. Statistically significant differences were assessed using Student's $t$-test

mice $(R+R$ mice), there was no 'diseased' mice. In group 5, levels of insulin just slightly exceeded the levels of insulin in group 1 (Figure 3a). There was a trend to higher levels of insulin-like growth factor (IGF)-1 in obese mice, however, not statistically significant (Figure $3 b$ ). Therefore, prevention of elevation of IGF-1 by rapamycin was not statistically significant also, probably requiring larger groups of animals to detect statistical effects of rapamycin on IGF-1 levels. Levels of glucose in mice on HFD were not significantly increased, and there was no effect of either resveratrol or rapamycin or their combination on glucose levels (Figure 3c). This may suggest that the elevated levels of insulin in HFDtreated mice compensated for potential insulin resistance. A decrease in insulin levels by a combination of rapamycin and resveratrol did not lead to increased glucose levels, consistent with sensitization to insulin by this drug combination. Levels of triglycerides were significantly increased on HFD (Figure 3d) and were not changed by any treatment. It was reported that rapamycin increases levels of triglycerides in mice and humans in part due to elevated lipolysis, which is a starvation-like side effect of rapamycin. ${ }^{24,25}$ However, at low doses used in our study, rapamycin did not affect triglycerides levels on HFD (Figure 3d).

Correlations between metabolic changes. There was a strong correlation between weight and insulin levels when two groups of mice on two different diets were combined (regular diet (RD) and HFD) (Figure 4a). Treatment with rapamycin and resveratrol decreased correlation, which still remained significant. (Figure $3 b$ ). There was no correlation between insuln and glucose levels (Figure 4c). Three superhyperinsulinemic ('diseased') mice had average glucose levels (Figure 4c). There was no statistically significant 

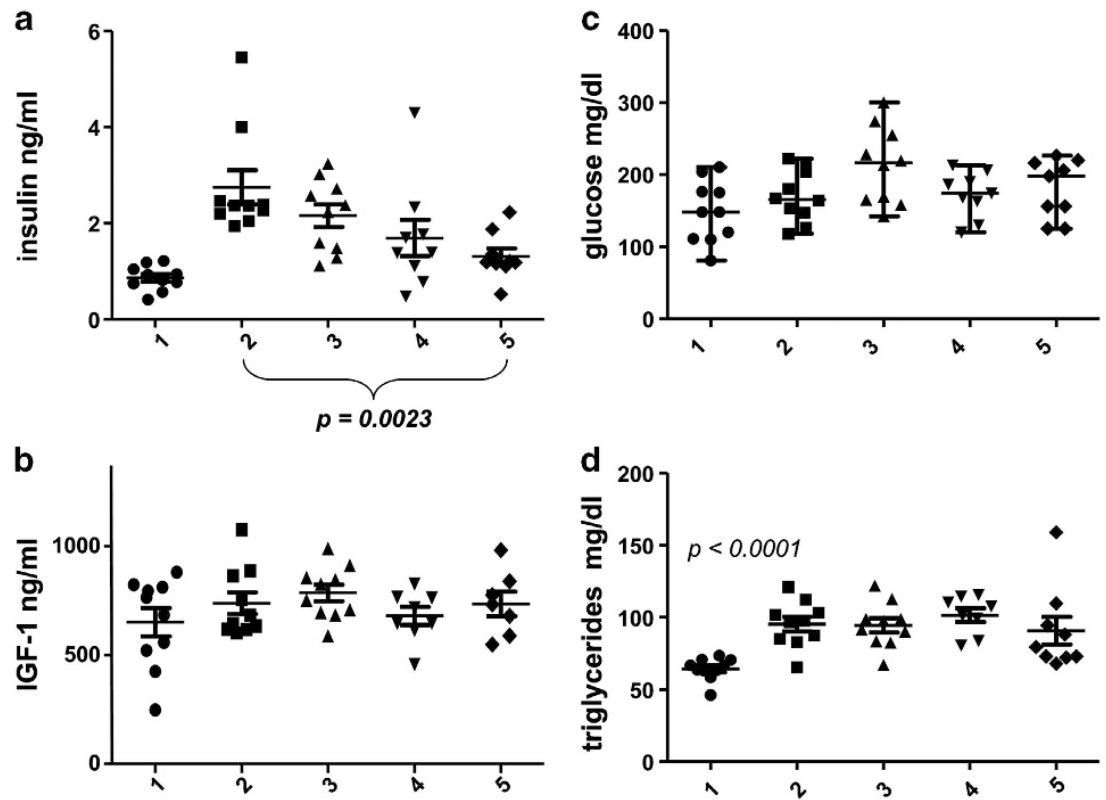

Figure 3 Blood levels of insulin (a), IGF-1 (b), glucose (c) and triglycerides (d) at the end of treatment. Mice onRD or HFD were treated with resveratrol, rapamycin or a combination of resveratrol and rapamycin for 13 weeks, as described in the legend of Figure 1. 1: RD; 2: HFD; 3: HFD + resv (resveratrol); 4: HFD + Rapa (rapamycin); 5: $\mathrm{HFD}+\mathrm{Re}+\mathrm{Ra}$ ( + resveratrol + rapamycin in combination). Fasting levels of insulin, glucose, triglycerides and IGF-1 in blood serum were determined at the end of the treatment. Data present mean \pm S.E.M for each group of mice. Statistically significant differences were assessed using Student's $t$-test
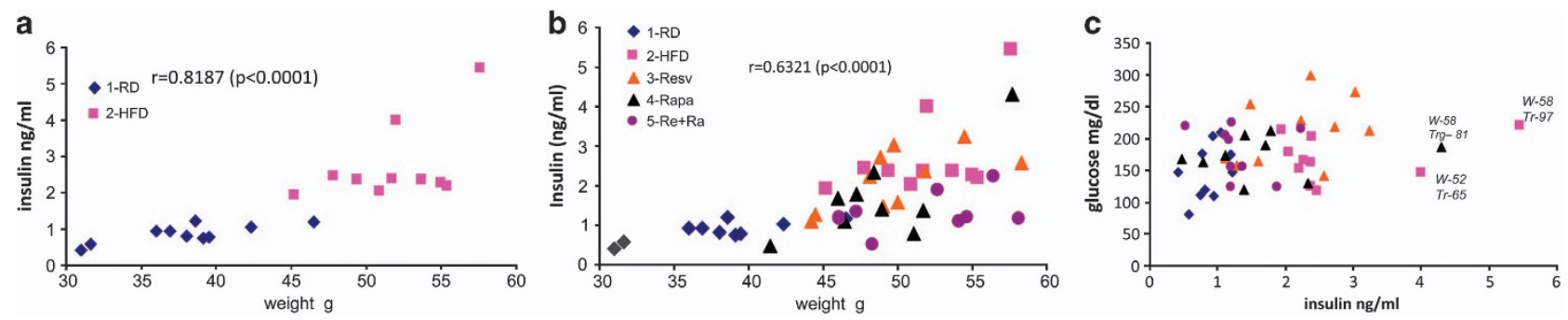

Figure 4 Correlation between insulin and weight ((a) untreated groups and (b) all groups) and insulin and glucose (c) in individual mice at the end of treatment. 1: RD; 2: HFD; 3: HFD + resv (resveratrol); 4: HFD + Rapa (rapamycin); 5: HFD + Re + Ra ( + resveratrol + rapamycin in combination). Correlation analyses Pearson $r$ coefficient and $P$ value (two tailed) were performed using GraphPad Prism version 5.00 for Windows

correlation between weight and triglycerides, and between glucose and triglycerides.

Resveratrol inhibits insulin-induced HIF-1-dependent response without inhibiting $\mathrm{mTOR}$. It was reported that resveratrol inhibited the mTOR pathway both upstream of and downstream from mTOR in cell culture. ${ }^{37,38}$ This might explain an additive effect of suboptimal doses of resveratrol and rapamycin observed in our animal study. However, inhibition of the mTOR pathway in cell culture was achieved at supra-pharmacological concentrations of resveratrol (10$100 \mu \mathrm{M})$, which are much higher than maximally achievable levels in animals and humans $(3 \mu \mathrm{M}) .^{38,40-43}$ Here, we investigated the effect of resveratrol on induction of HIF-1 by insulin in retinal pigment epithelial (RPE cells). In RPE cells, insulin induces HIF-1-dependent transcription, detectable by induction of luciferase expressed under promoter containing three HIF-1-responsive elements (HRE-Luc).
Specifically, insulin activates mTOR, leading to induction of HRE-Luc. ${ }^{44}$ Rapamycin at sub-nanomolar concentrations completely blocked insulin-induced phosphorylation of S6 (a marker of mTOR activity) and prevented induction of HRELuc. $^{44}$ This is an extremely sensitive assay for mTOR activation. As shown here, insulin induced pS6 phosporylation in RPE cells (Figure 5a). Resveratrol at concentrations above $12 \mu \mathrm{M}$ inhibited pS6 with maximal effect at $50 \mu \mathrm{M}$. Despite the lack of mTOR inhibition at doses below $12 \mu \mathrm{M}$, resveratrol still inhibited HRE-Luc expression at concentrations as low as $200 \mathrm{~nm}$ (Figure 5b), suggesting that the inhibition of insulin-induced HRE-Luc is mTOR-independent. To confirm that this is selective abrogation of insulin-induced effects, we also investigated fetal bovine serum (FBS)induced HRE-Luc (Figures 5c-d). Resveratrol inhibited FBSinduced pS6 at concentrations above $25 \mu \mathrm{M}$, and at these concentrations it strongly blocked HRE-Luc (Figures 5c-d). Resveratrol only marginally inhibited HRE-Luc at lower 
a
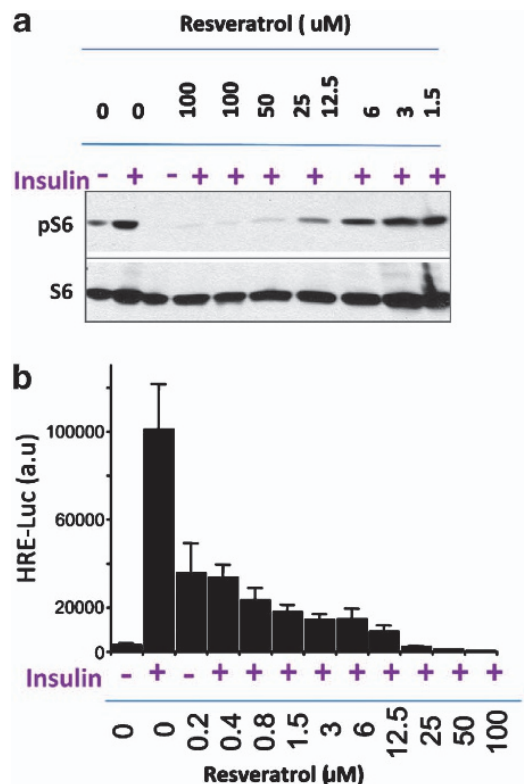

C

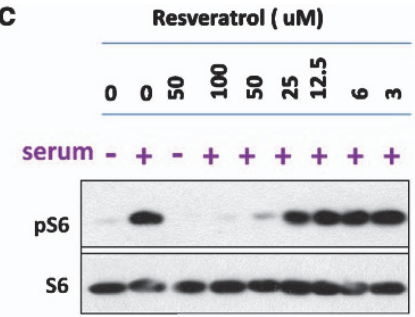

d

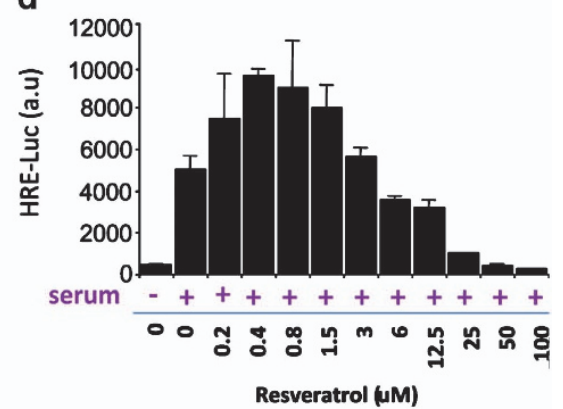

Figure 5 Effects of resveratrol on MTOR-dependent induction of HIF-1-responsive transcription in RPE cells. (a), (c): immunoblot analysis. RPE cells were plated in 10\% serum-MEM, and the next day, the medium was changed for serum-free MEM for one day before treatment. In serum-free MEM cells were treated with indicated concentrations of resveratrol followed by either insulin (a) or serum (c). Then the cells were lysed and immunoblot for pS6 and S6 was performed. (b), (d): HIF-1-responsive luciferase induction. Cells were transfected with HRE -Luc (HIF-responsive-luciferase construct) as described previously. The next day, cells were treated with were treated with indicated concentrations of resveratrol followed by either insulin (b) or serum (d). After $16 \mathrm{~h}$, cells were lysed and luciferase activity was measured

(6-12 $\mu \mathrm{M})$ concentrations. Most importantly, it did not inhibit, but instead stimulated FBS-induced HRE-Luc at pharmacological concentration (below $3 \mu \mathrm{M}$ ). This may be an example of hormesis. ${ }^{45,46}$

Effects of resveratrol and rapamycin on mTOR-dependent senescence in cell culture. Next we investigated effects of pharmacological and supra-pharmacological concentrations of resveratrol on mTOR-dependent geroconversion, a conversion from reversible cell cycle arrest to irreversible senescence. We have previously shown that rapamycin suppresses geroconversion in HT-p21 cells. ${ }^{47-49}$ In these cells, induction of p21 by isopropyl-thio-galactosidase (IPTG) initially causes reversible arrest, which becomes irreversible senescence after 3 days. After 3 days, cells cannot restart proliferation and cannot form colonies when IPTG is washed out. As shown here (Figure 6a), only a few colonies formed from IPTG-treated cells. Rapamycin (added together with IPTG) suppressed geroconversion and prevented the loss of regenerative/replicative potential (RP), so that cells formed colonies after removal of IPTG and rapamycin. We investigated whether resveratrol potentiates the ability of rapamycin to suppress geroconversion and to prevent the loss of RP. As shown in Figure $6 \mathrm{a}, 50 \mu \mathrm{m}$ resveratrol alone (but not $10 \mu \mathrm{M}$ ) significantly prevented the loss of RP in IPTG-arrested cells. At $50 \mu \mathrm{m}$ resveratrol slightly, but insignificantly potentiated the effect of suboptimal concentration of rapamycin ( $5 \mathrm{~nm})$, and there was no additive effect of resveratrol with $500 \mathrm{nM}$ rapamycin (Figure 6a). It was previously shown that resveratrol inhibited pS6 in HTp21 cells at concentrations exceeding $40-50 \mu \mathrm{M} .{ }^{38}$ Here, we confirmed that at pharmacological concentrations (below
$3 \mu \mathrm{M})$ resveratrol did not inhibit mTOR in proliferating and IPTG-arrested HT-p21 cells (Figure 6b). At pharmacological concentrations, resveratrol did not suppress 'chronological senescence' (CS), ${ }^{50}$ which was effectively suppressed by rapamycin (Figure 6c). CS in mammalian cells is analogous to chronological aging in yeast, and is inhibited by rapamycin in both systems. ${ }^{4,51,50}$ In mammalian cells, CS is caused by self-poisoning of the cells by accumulated lactic acid. ${ }^{50}$ In fact, unlike rapamycin, resveratrol did not decrease levels of lactic acid in high-density cultures (Figure 6d). We conclude that resveratrol does not display rapamycin-like effects at pharmacological (non-toxic) concentrations.

\section{Discussion}

Resveratrol and rapamycin are two of the most studied antiaging agents with the potential to delay age-related diseases in mammals. Although many beneficial effects of rapamycin and resveratrol are overlapping, they are not identical. For example, rapamycin slows down aging in mammals, whereas resveratrol increases insulin sensitivity in mice on HFD. Surprisingly, a combination of resveratrol and rapamycin has never been studied. Here, we demonstrated that low-dose rapamycin and resveratrol prevented hyperinsulinemia in male mice on HFD. Hyperinsulinemia is one of key risk factors of age-related diseases, such as cancer, atherosclerosis and diabetic complications. ${ }^{52}$ Obesity is often associated with hyperinsulinemia. In contrast, calorie restriction leads to a decrease in levels of insulin. ${ }^{53}$ Hyperinsulinemia is associated with aging and poor health. In contrast, centenarians and their relatives tend to have low insulin levels. ${ }^{54}$ Here, we demonstrated that a combination of rapamycin with resveratrol 
a

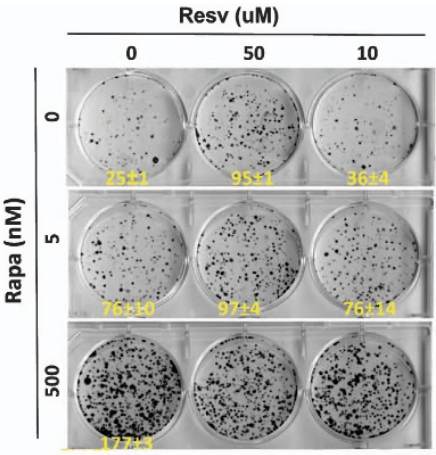

b

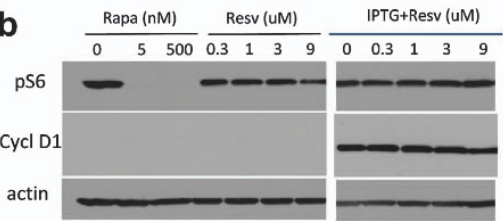

C
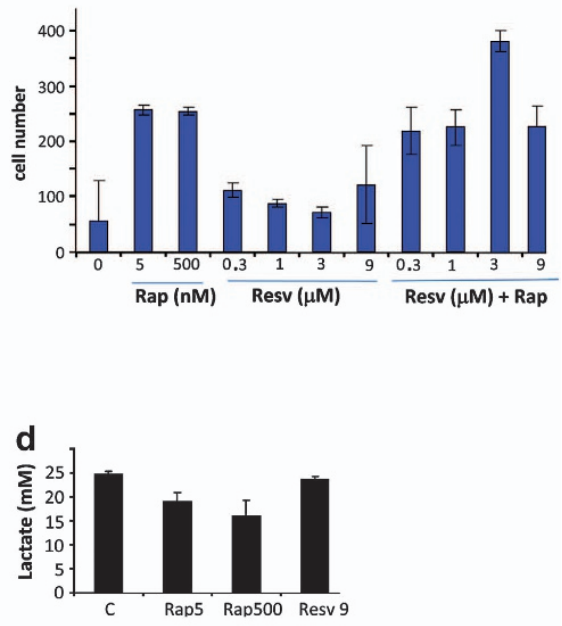

Figure 6 Effects of resveratrol on p21-induced senescence and 'chronological senescence' in HT-p21 cells. a, b: Effect of resveratrol on senescence induced by p21 induction in HT-p21 cells. (a). Replicative/regenerative potential. HT-p21 cells were treated with IPTG in the presence or absence of resveratrol and/or rapamycin at 5 and $500 \mathrm{~nm}$ for 3 days, and then cells were washed and allow to regrow for 7 days. Colonies were stained with Crystal violet. Data present mean \pm STD from triplicate wells. b. HTp21 cells were treated with resveratrol, rapamycin or resveratrol + IPTG for $24 \mathrm{~h}$. Immunoblotting was performed with the indicated antibodies $\mathbf{c}$. Effect of resveratrol or its combination with rapamycin on 'chronological senescence' of HT-p21 cells. Cells were plated in high density in the presence or absence of indicated concentrations of resveratrol (Resv) and/or rapamycin (Rap). Rap in $\mathrm{nM}$ and Resv in $\mu \mathrm{M}$. After 4 days, cells were trypsinized and an aliquots of cells were replated and allowed to regrow. After 6 days cells were counted. Data present mean \pm S.E.M. from triplicate wells $\mathrm{d}$. HT-p21 cells were treated as in C. Lactate concentration was determined in conditioned medium on Day 3. Data present mean \pm S.E.M. from triplicate wells

prevented hyperinsulinemia induced by HFD. There was no effect on triglyceride and glucose levels, probably suggesting insulin sensitization by the combination of rapamycin and resveratrol. It is important to emphasize that rapamycin was administered in intermittent (for mice) fashion. Our preliminary data demonstrated that mTOR is not inhibited in mice, who received rapamycin via gavage the day before, consistent with intermittent effect of every other day oral rapamycin administration in mice. Lack of biological effects of rapamcin on the next day after administration is expected in mice, given extremely short half life of rapamycin in mice (less than $6 \mathrm{~h}$ ) (Ref. 16), which is at least ten time less than its half life in humans. Noteworthy, intermittent fasting (every other day) has profound health benefits even without causing weight loss. ${ }^{55}$ Resveratrol has numerous targets including the mTOR pathway. Yet, in most studies, in order to inhibit mTOR, resveratrol was used at concentrations between 10 and $150 \mu \mathrm{M},{ }^{37,38,41}$ which exceed maximal achievable concentration in blood. ${ }^{41-43}$ At doses below $10 \mu \mathrm{M}$ resveratrol did not block the mTOR pathway. Yet, like rapamycin, resveratrol prevented HIF-1-dependent transcription caused by insulin, in other words, preventing this 'side effect' of insulin. There are many other effects of rapamycin and resveratrol that might be additive. Resveratrol is effective to decrease vascular lesions and VEGF induction in mouse retinas of early diabetes. ${ }^{56}$ Rapamycin decreased retinopathy without decreasing VEGF levels. ${ }^{57}$ Resveratrol increases insulin sensitivity in mice, whereas the effect of rapamycin depends on the duration and doses of treatment. Rapamycin, but not resveratrol, extends life span of genetically heterogeneous mice..$^{9,10,58}$ Our study suggests that resveratrol can be combined with rapamycin to maximize its beneficial effects, and to possibly prevent side effects of each other.

\section{Materials and Methods}

Materials for animal administration. Resveratrol was kindly provided by Dr. David Sinclair (Harvard Medical School, Boston, MA, USA). Resveratrol was dissolve in ethanol as $100 \mathrm{mg} / \mathrm{ml}$ stock solution. Before gavage, resveratrol stock $(100 \mathrm{mg} / \mathrm{ml})$ solution was diluted in water to a final concentration of $20 \mathrm{mg} / \mathrm{ml}$. Rapamune (Sirolimus, rapamycin) oral solution $(1 \mathrm{mg} / \mathrm{ml})$ was purchased from Cardinal Health (Syracuse, NY, USA) and diluted with PBS containing 5\% Tween80 (Sigma-Aldrich, St Louis, MO, USA), 5\% PEG (Sigma-Aldrich) and 4\% ethanol. All treatments were administered as gavage 3 times a week (every other day).

Mice. All animal studies were conducted in accordance with the regulations of the Committee of Animal Care and Use at Roswell Park Cancer Institute. A total of 50 male mice of $\mathrm{C} 57 \mathrm{BL} / 6 \mathrm{NCr}$ strain, 9 months old, were randomly assigned to control and experimental groups. Mice were kept in polypropylene cages $(30 \times$ $21 \times 10 \mathrm{~cm}$ ) under standard light/dark regimen (12 h light: $12 \mathrm{~h}$ darkness) at $22 \pm 2{ }^{\circ} \mathrm{C}$. One group of mice received standard laboratory chow (5\% fat- RD) and served as a normal control. Four other groups, received high fat $60 \%$ diet (Research Diets, Inc Cat no. D12492 Rodent Diet 60\% kCal\% fat). Four groups on HFD included: group 2 (HFD)-mice on HFD without treatment served as HFD control; group 3 (HFD + Re)-mice on HFD treated with $200 \mathrm{mg}$ per $\mathrm{kg}$ resveratrol; group 4 (HFD + Ra) mice on HFD treated with rapamune (Sirolimus, rapamycin) $1.5 \mathrm{mg} / \mathrm{kg}$ and group 5 (HFD $+\mathrm{Re}+\mathrm{Ra}$ ) mice on HFD treated with a combination of $200 \mathrm{mg}$ per $\mathrm{kg}$ resveratrol and $1.5 \mathrm{mg}$ per $\mathrm{kg}$ rapamune. All treatments were administered as gavage 3 times a week (every other day). All mice received water ad libitum. Animal weight was determined weekly. After 3 months drug treatment was discontinued for 1 day, mice were fasted overnight, and fasted blood was collected from all the mice. Glucose levels were measured directly in blood upon collection using Accu-Chek Aviva strips (McKesson, Atlanta, GA, USA). Sera were prepared and used for biochemical analyses.

Insulin concentration in blood sera was measured using Insulin (Mouse) Ultrasensitive ELISA kit (ALPCO Diagnostics, Salem, NH, USA) according to manufacture's protocol. Data were analyzed using range of insulin standards and four parameter logistic fit. 
IGF-1 concentration in blood sera was determined using IGF-1 (Mouse/Rat) ELISA kit (ALPCO Diagnostics, Salem, NH) according to manufacture's protocol. Data were analyzed using range of IGF-1 standards and four parameter logistic fit. Concentration of triglycerides was measured using triglyceride Colorimetric Assay kit (Cayman Chemical Company, Ann Arbor, MI, USA) according to manufacture's protocol. Data were analyzed using range of triglyceride standards and linear regression.

Statistical analyses were performed using GraphPad Prizm 5.00 for Windows, GraphPad Software, San Diego, CA, USA, www.graphpad.com'.

Or ( $t$-test and correlation analyses (Pearson $r$ coefficient and $P$ value (two tailed) were performed using GraphPad Prism version 5.00 for Windows, GraphPad Software, San Diego, CA, USA www.graphpad.com).

Cell lines. HT-p21 cells, derived from HT1080 human fibrosarcoma cells (ATCC, Manassas, VA, USA), were previously described. ${ }^{47,59,60} \mathrm{HT}$-p21 cells in high-glucose DMEM without pyruvate supplemented with $\mathrm{FC} 2$ serum (HyClone FetalClone II from Thermo Scientific, Logan, UT, USA). In HT-p21 cells, p21 can be turned on or off using IPTG. ${ }^{59}$ RPE cells were used by us previously. ${ }^{44,47}$ HRE-Luc assay was performed as previously described. ${ }^{44}$

Immunoblot analysis. Cells were lysed in $1 \% \mathrm{SDS} / 10 \mathrm{mM}$ Tis. $\mathrm{HCl}, \mathrm{pH} 7.4$ lysis buffer and subjected to SDS-PAGE using mini gradient gels or gradient Criterion gels (Bio-Rad, Hercules, CA, USA), followed by transfer onto PVDF membranes. After blotting with respective antibodies, blots were processed with SuperSignal West Pico Chemiluminescent Substrate (Thermo Scientific, Rockford, IL, USA) and exposed to BioBlot BXR film (Laboratory Products Sales, Inc, Rochester, NY, USA). Rabbit antiphospho S6 (Ser 235/236) and mouse anti-S6 antibodies were from Cell Signaling Biotechnology (Danvers, MA, USA); mouse anticyclin D1and rabbit antiactin antibodies were from Santa Cruz Biotechnology (Santa Cruz, CA, USA) and Sigma-Aldrich, respectively. Secondary antibodies were from Cell Signaling Biotechnology.

Colony formation assay. Cells were plated at low density, treated with a senescence-inducing agent (IPTG) for 4 days in the presence or absence of resveratrol and/or rapamycin as previously described. ${ }^{49}$ Then, drugs were washed off, and cells were incubated in fresh drug-free medium 7 days. Plates were fixed and stained with $1.0 \%$ crystal violet. Colonies were counted.

Replicative viability as a measure of 'chronological senescence'. Cells were plated at high initial density and cultured for 4 days as described previously. ${ }^{50}$ Then media with floating (dead cells) were removed, cells trypsinized, and a small aliquot of attached cells was replated at low cell density in 6 -well plates in fresh medium. After 6 days cells were trypzinised and counted.

Lactic acid concentrations in growth medium were measured using L-Lactate assay kit from Eton Bioscience Inc (San Diego, CA, USA) according to manufacture's instructions.

\section{Conflict of Interest}

The authors declare no conflict of interest.

Acknowledgements. We thank RPCl and Wilmot Center for support. This work was funded in part by RPCI/Wilmot collaborative 2011-12 grant to MV Blagosklonny. He also is a consultant of Tartis-Aging.

1. Stipp D. A new path to longevity. Sci Am 2012; 306: 32-39.

2. Kapahi P, Chen D, Rogers AN, Katewa SD, Li PW, Thomas EL et al. With TOR, less is more: a key role for the conserved nutrient-sensing TOR pathway in aging. Cell Metab 2010; 11: 453-465

3. Kaeberlein M, Kennedy BK. Hot topics in aging research: protein translation and TOR signaling, 2010. Aging Cell 2011; 10: 185-190.

4. Powers RWr, Kaeberlein M, Caldwell SD, Kennedy BK, Fields S. Extension of chronological life span in yeast by decreased TOR pathway signaling. Genes Dev 2006; 20: 174-184.

5. Blagosklonny MV. Rapamycin and quasi-programmed aging: Four years later. Cell Cycle 2010; 9: 1859-1862.

6. Blagosklonny MV. Prospective treatment of age-related diseases by slowing down aging. Am J Pathol 2012; 181: 1142-1146.

7. Dazert E, Hall MN. mTOR signaling in disease. Curr Opin Cell Biol 2011; 23: 744-755.
8. Bjedov I, Partridge L. A longer and healthier life with TOR down-regulation: genetics and drugs. Biochem Soc Trans 2011; 39: 460-465.

9. Harrison DE, Strong R, Sharp ZD, Nelson JF, Astle CM, Flurkey K et al. Rapamycin fed late in life extends lifespan in genetically heterogenous mice. Nature 2009; 460: 392-396.

10. Miller RA, Harrison DE, Astle CM, Baur JA, Boyd AR, de Cabo R et al. Rapamycin, but not resveratrol or simvastatin, extends life span of genetically heterogeneous mice. J Gerontol A Biol Sci Med Sci 2011; 66: 191-201.

11. Wilkinson JE, Burmeister L, Brooks SV, Chan CC, Friedline S, Harrison DE et al. Rapamycin slows aging in mice. Aging Cell 2012; 11: 675-682.

12. Spong A, Bartke A. Rapamycin slows aging in mice. Cell Cycle 201211.

13. Anisimov VN, Zabezhinski MA, Popovich IG, Piskunova TS, Semenchenko AV, Tyndyk ML et al. Rapamycin increases lifespan and inhibits spontaneous tumorigenesis in inbred female mice. Cell Cycle 2011; 10: 4230-4236.

14. Anisimov VN, Zabezhinski MA, Popovich IG, Piskunova TS, Semenchenko AV, Tyndyk ML et al. Rapamycin extends maximal lifespan in cancer-prone mice. Am J Pathol 2010; 176: 2092-2097.

15. Komarova EA, Antoch MP, Novototskaya LR, Chernova OB, Paszkiewicz G, Leontieva OV et al. Rapamycin extends lifespan and delays tumorigenesis in heterozygous p53 + I mice. Aging (Albany NY) 2012; 4: 709-714.

16. Comas M, Toshkov I, Kuropatwinski KK, Chernova OB, Polinsky A, Blagosklonny MV et al. New nanoformulation of rapamycin Rapatar extends lifespan in homozygous p53-/- mice by delaying carcinogenesis. Aging (Albany NY) 2012; 4: 715-722.

17. Chang GR, Chiu YS, Wu YY, Chen WY, Liao JW, Chao TH et al. Rapamycin protects against high fat diet-induced obesity in C57BL/6J mice. J Pharmacol Sci 2009; 109: 496-503.

18. Lamming DW, Ye L, Katajisto P, Goncalves MD, Saitoh M, Stevens DM et al. Rapamycininduced insulin resistance is mediated by mTORC2 loss and uncoupled from longevity. Science 2012; 335: 1638-1643.

19. Fraenkel M, Ketzinel-Gilad M, Ariav Y, Pappo O, Karaca M, Castel J et al. mTOR inhibition by rapamycin prevents beta-cell adaptation to hyperglycemia and exacerbates the metabolic state in type 2 diabetes. Diabetes 2008; 57: 945-957.

20. Chang GR, Wu YY, Chiu YS, Chen WY, Liao JW, Hsu HM et al. Long-term administration of rapamycin reduces adiposity, but impairs glucose tolerance in high-fat diet-fed KK/HIJ mice. Basic Clin Pharmacol Toxicol 2009; 105: 188-198.

21. Deblon N, Bourgoin L, Veyrat-Durebex C, Peyrou M, Vinciguerra M, Caillon A et al. Chronic mTOR inhibition by rapamycin induces muscle insulin resistance despite weight loss in rats. Br J Pharmacol 2012; 165: 2325-2340.

22. Houde VP, Brule S, Festuccia WT, Blanchard PG, Bellmann K, Deshaies Y et al. Chronic rapamycin treatment causes glucose intolerance and hyperlipidemia by upregulating hepatic gluconeogenesis and impairing lipid deposition in adipose tissue. Diabetes 2010; 59: $1338-1348$.

23. Yang SB, Lee HY, Young DM, Tien AC, Rowson-Baldwin A, Shu YY et al. Rapamycin induces glucose intolerance in mice by reducing islet mass, insulin content, and insulin sensitivity. J Mol Med (Berl) 2011; 90: 575-585.

24. Blagosklonny MV. Rapamycin-induced glucose intolerance: Hunger or starvation diabetes. Cell Cycle 2011; 10: 4217-4224.

25. Blagosklonny MV. Once again on rapamycin-induced insulin resistance and longevity: despite of or owing to. Aging (Albany NY) 2012; 4: 350-358.

26. Baur JA, Sinclair DA. Therapeutic potential of resveratrol: the in vivo evidence. Nat Rev Drug Discov 2006; 5: 493-506.

27. Morselli E, Maiuri MC, Markaki M, Megalou E, Pasparaki A, Palikaras K et al. Caloric restriction and resveratrol promote longevity through the Sirtuin-1-dependent induction of autophagy. Cell Death Dis 2010; 1: e10.

28. Timmers S, Auwerx J, Schrauwen P. The journey of resveratrol from yeast to human. Aging (Albany NY) 2012; 4: 146-158.

29. Baur JA, Pearson KJ, Price NL, Jamieson HA, Lerin C, Kalra A et al. Resveratrol improves health and survival of mice on a high-calorie diet. Nature 2006; 444: 337-342.

30. Lagouge M, Argmann C, Gerhart-Hines Z, Meziane H, Lerin C, Daussin F et al. Resveratrol improves mitochondrial function and protects against metabolic disease by activating SIRT1 and PGC-1alpha. Cell 2006; 127: 1109-1122.

31. Kang W, Hong HJ, Guan J, Kim DG, Yang EJ, Koh G et al. Resveratrol improves insulin signaling in a tissue-specific manner under insulin-resistant conditions only: in vitro and in vivo experiments in rodents. Metabolism 2012; 61: 424-433.

32. Brasnyo P, Molnar GA, Mohas M, Marko L, Laczy B, Cseh J et al. Resveratrol improves insulin sensitivity, reduces oxidative stress and activates the Akt pathway in type 2 diabetic patients. Br J Nutr 2011; 106: 383-389.

33. Milne JC, Lambert PD, Schenk S, Carney DP, Smith JJ, Gagne DJ et al. Small molecule activators of SIRT1 as therapeutics for the treatment of type 2 diabetes. Nature 2007; 450 712-716.

34. Baur JA, Chen D, Chini EN, Chua K, Cohen HY, de Cabo R et al. Dietary restriction: standing up for sirtuins. Science 2010; 329: 1012-1013; author reply 1013-1014.

35. Vetterli L, Maechler P. Resveratrol-activated SIRT1 in liver and pancreatic beta-cells: a Janus head looking to the same direction of metabolic homeostasis. Aging (Albany NY) 2011; 3: 444-449. 
36. Price NL, Gomes AP, Ling AJ, Duarte FV, Martin-Montalvo A, North BJ et al. SIRT1 is required for AMPK activation and the beneficial effects of resveratrol on mitochondrial function. Cell Metab 2012; 15: 675-690.

37. Armour SM, Baur JosephA, Sherry N, Hsieh SN, Land-Bracha A, Thomas SM et al. Inhibition of mammalian S6 kinase by resveratrol suppresses autophagy. Aging 2009; 1 515-528.

38. Demidenko ZN, Blagosklonny MV. At concentrations that inhibit mTOR, resveratrol suppresses cellular senescence. Cell Cycle 2009; 8: 1901-1904.

39. Blagosklonny MV. Linking calorie restriction to longevity through sirtuins and autophagy: any role for TOR. Cell Death Dis 1: e12 2010; doi:10.1038/cddis.2009.17.

40. Scott E, Steward WP, Gescher AJ, Brown K. Resveratrol in human cancer chemoprevention-choosing the 'right' dose. Mol Nutr Food Res 2012; 56: 7-13.

41. Gescher AJ, Steward WP. Relationship between mechanisms, bioavailibility, and preclinical chemopreventive efficacy of resveratrol: a conundrum. Cancer Epidemio Biomarkers Prev 2003; 12: 953-957.

42. Boocock DJ, Patel KR, Faust GE, Normolle DP, Marczylo TH, Crowell JA et al. Quantitation of trans-resveratrol and detection of its metabolites in human plasma and urine by high performance liquid chromatography. J Chromatogr B Analyt Technol Biomed Life Sci 2007 848: $182-187$.

43. Boocock DJ, Faust GE, Patel KR, Schinas AM, Brown VA, Ducharme MP et al. Phase dose escalation pharmacokinetic study in healthy volunteers of resveratrol, a potential cancer chemopreventive agent. Cancer Epidemiol Biomarkers Prev 2007; 16: 1246-1252.

44. Demidenko ZN, Blagosklonny MV. The purpose of the HIF-1/PHD feedback loop: to limit mTOR-induced HIF-1alpha. Cell Cycle 2011; 10: 1557-1562.

45. Calabrese EJ, Mattson MP, Calabrese V. Resveratrol commonly displays hormesis: occurrence and biomedical significance. Hum Exp Toxicol 2010; 29: 980-1015.

46. Martins I, Galluzzi L, Hormesis KroemerG. cell death and aging. Aging (Albany NY) 2011 3: 821-828.

47. Demidenko ZN, Zubova SG, Bukreeva El, Pospelov VA, Pospelova TV, Blagosklonny MV. Rapamycin decelerates cellular senescence. Cell Cycle 2009; 8: 1888-1895.

48. Demidenko ZN, Korotchkina LG, Gudkov AV, Blagosklonny MV. Paradoxical suppression of cellular senescence by p53. Proc Natl Acad Sci USA 2010; 107: 9660-9664.

49. Leontieva OV, Natarajan V, Demidenko ZN, Burdelya LG, Gudkov AV, Blagosklonny MV. Hypoxia suppresses conversion from proliferative arrest to cellular senescence. Proc Natl Acad Sci USA 2012; 109: 13314-13318.

50. Leontieva OV, Blagosklonny MV. Yeast-like chronological senescence in mammalian cells: phenomenon, mechanism and pharmacological suppression. Aging (Albany NY) 2011; 3 1078-1091.
51. Burtner CR, Murakami CJ, Kennedy BK, Kaeberlein M. A molecular mechanism of chronological aging in yeast. Cell Cycle 2009; 8: 1256-1270.

52. Anisimov VN. Metformin for aging and cancer prevention. Aging (Albany NY) 2010; 2: 760-774

53. Fontana L, Klein S, Holloszy JO. Effects of long-term calorie restriction and endurance exercise on glucose tolerance, insulin action, and adipokine production. Age (Dordr) 2010; 32: $97-108$.

54. Paolisso G, Gambardella A, Ammendola S, D'Amore A, Balbi V, Varricchio M et al. Glucose tolerance and insulin action in healty centenarians. Am J Physiol 1996; 270: E890-E894.

55. Mattson MP, Wan R. Beneficial effects of intermittent fasting and caloric restriction on the cardiovascular and cerebrovascular systems. J Nutr Biochem 2005; 16: 129-137.

56. Kim YH, Kim YS, Roh GS, Choi WS, Cho GJ. Resveratrol blocks diabetes-induced early vascular lesions and vascular endothelial growth factor induction in mouse retinas. Acta Ophthalmol 2012: 90: e31-e37.

57. Kolosova NG, Muraleva NA, Zhdankina AA, Stefanova NA, Fursova AZ, Blagosklonny MV. Prevention of age-related macular degeneration (AMD)-like retinopathy by rapamycin in rats. Am J Pathol 2012; 181: 472-477.

58. Strong R, Miller RA, Astle CM, Baur JA, de Cabo R, Fernandez E et al. Evaluation of Resveratrol, Green Tea Extract, Curcumin, Oxaloacetic Acid, and Medium-Chain Triglyceride Oil on Life Span of Genetically Heterogeneous Mice. J Gerontol A Biol Sci Med Sci 2012; 68: 6-16.

59. Chang BD, Xuan Y, Broude EV, Zhu H, Schott B, Fang J et al. Role of p53 and p21waf1/ cip1 in senescence-like terminal proliferation arrest induced in human tumor cells by chemotherapeutic drugs. Oncogene 1999; 18: 4808-4818.

60. Chang BD, Broude EV, Fang J, Kalinichenko TV, Abdryashitov R, Poole JC et al. p21Waf1/ Cip1/Sdi1-induced growth arrest is associated with depletion of mitosis-control proteins and leads to abnormal mitosis and endoreduplication in recovering cells. Oncogene 2000; 19: $2165-2170$.

Cell Death and Disease is an open-access journal published by Nature Publishing Group. This work is licensed under the Creative Commons Attribution-NonCommercial-No Derivative Works 3.0 Unported License. To view a copy of this license, visit http://creativecommons.org/licenses/by-nc-nd/3.0/ 